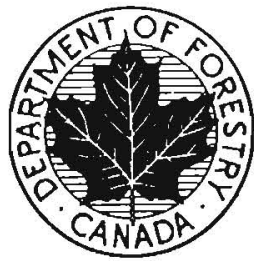

\title{
Describing Forest Fires - Old Ways and New
}

by

C. E. VAN WAGNER

Reprinted from 7he Forestry Chronicle. September. 1965, Vol. 41. No. 3 


\title{
DESCRIBING FOREST FIRES — OLD WAYS AND NEW
}

\author{
By C. E. VAN WAGNER
}

\section{ABSTRACT}

This article deals with several ways of describing forest fires and their limitations. The simplest and oldest way is by simple verbal description. Then came the combination of rate of spread and resistance to control. The best quantitative measure of fire behaviour, however, is the rate of energy output per unit of fire front, quoted in conjunction with the linear rate of spread. If the full benefits of advances in fire control technology are to be realized, wider use of the energy output concept will probably be necessary, first among fire researchers and eventually among fire control people.

\section{RESUME}

La présente publication traile de plusieurs méthodes de description de feux de forêt el de certaines lacunes inhérentes à ces méthodes. La description verbale constitute la plus simple et la plus ancienne de ces méthodes. On en est venu ensuite à adopter les notions combinées de la vitesse de propagation du feu, et de la résistance de celui-ci à la répression. La meilleure estimation quantitative de l'intensité des feux, toutefois, s'obtient en calculant conjointement le taux d'énergie dissipée par unité de front du feu, et la vitesse linéaire de propogation. Si l'on désire tirer plein profit des progès réalisés dans la technologie de la protection contre le fell, il faudra probablement vulgariser le principe de la description d'un feu en fonction de l'énergie dissipée, d'abord parmi les spécialistes de la recherche sur les feux de forêt et, éventuellement. parmi tous ceux qui chargés de la répression.

The last few decades have seen great strides in the development of equipment and techniques for extinguishing forest fires, yet ways of describing forest fires have meanwhile remained much the same. Whether better descriptions of forest fires are necessary is certainly a matter of opinion; many fire control organizations keep little or no formal record of what their fires were like. But among people dealing with forest fires are some who wish to compare one fire with another and are finding the traditional means of description inadequate. This article deals with several different approaches to forest fire description and their limitations.

The simplest way to report a forest fire is by mere verbal description. A fire is said to be burning in the ground, on the surface or in the crowns; it may smoulder, creep, run, roll, crown or spot; it may be "cool" or "hot". As a scientific description, this approach has obvious weaknesses. No one knows exactly what another means by these terms, and a full fire description

\footnotetext{
${ }^{2}$ Fire Research Officer, Petawawa Foresc Experiment Station, Chalk River, Ontario.
} 
may amount to a small essay. There is no possibility of systematically comparing many fires in different fuels or in the same fuels under different weather conditions. The limitations of verbal description are most apparent for intense fires; anyone can test this difficulty by interviewing a number of witnesses to the same fire. Nevertheless, among experienced people working together verbal description is useful and necessary, and some element of verbal description will no doubt always be advisable in the record, no matter how sophisticated fire description eventually becomes.

The first attempt at objective comparative fire description was by Hornby (1935), with his classic method of rating fuel types by rate of spread and resistance to control. Although he used this approach mainly to prepare fuel maps, the terms were really fire descriptions and the maps really fire behaviour maps. Rate of spread meant rate of perimeter increase, and resistance to control referred to the effort required to stop the fire by hand tools. Hornby rated each factor low, medium, high or extreme, and made the scheme quantitative by quoting rate of spread in chains of perimeter-increase per hour and resistance to control in man-hours per chain of held line. The product of the two, in man-hours per hour, gave the size of the control force needed to keep up with the fire.

This approach had distinct advantages over simple verbal description, especially in its quantitative sense. Provided rate of spread and control effort could be measured, one fire could be compared with another in a definite way, and fire descriptions could be systematically recorded. Unfortunately, it has nowhere proved possible to maintain this scheme on a quantitative basis. Rate of spread can of course be measured (more about this later), but the concept of resistance to control has several fundamental limitations. First, it can be easily applied only with uniform fire-fighting methods; bulldozers, power pumps and aircraft have made it practically impossible to quote resistance to control in terms of the work required to put out the fire. Second, it provides no way of describing those fires whose control lines are lost again and again before being held, or those that burn until put out by rain. Third, it presumes a certain standard of fire-fighting efficiency, itself difficult to describe. Fourth, the effect of topography becomes enmeshed in the fire behaviour rating. Hornby's resistance to control has thus become a relative rating. It provides common terms of reference, but suffers the same weaknesses as verbal description-no one knows exactly what another means by low. medium, high or extreme, and there is no way of stating the order of difference between one rating and another. Sixteen years after Horuby, Barrows (1951) ignored resistance to control in his treatise on fire behaviour in the Rocky Mountains, and used rate of spread as the sole numerical measure of behaviour.

Of all the properties of forest fires that might be considered as yardsticks of behaviour, rate of spread is the one most easily understood and measured. It may be thought of as linear (i.e., the rate of advance at one point of the front) or as rate of perimeter increase. If a fire advances equally fast in all directions, then the rate of perimeter increase is $2 \pi$ or about six times the linear rate of spread. At the other extreme, if the fire after attaining a certain size advances on one front only, then the rate of perimeter increase 
is only twice the linear rate, and the additional front is all flank fire. Many fires spread so that the perimeter rate is about three times the linear rate. The linear rate is obviously the more fundamental of the two, and affects directly the way the fire must be fought at each point. Rate of perimeter increase is a useful but general measure that obscures the large difference between linear rates at head, flank, and rear. Each sense has its uses. The rate of spread (linear or perimeter) remains constant regardless of the fire's area, provided the burning conditions do not change. Perhaps the term itself is a bit unfortunate, since the word "spread" suggests area rather than distance or length of perimeter. The rate of area increase, however, is not constant; rather, the area burned at constant rate of spread increases as the square of the time elapsed since ignition.

The rate of spread alone tells the fire control officer a great deal about a fire, particularly where he must go to meet it and how he must deploy his forces. But rate of spread says nothing directly about what the fire is like at a given moment, or how closely it may be approached. The expression "fire intensity" is often used to express this aspect of forest fire behaviour, but rarely with any definition of what is meant. To complement rate of spread, we need a quantitiative measure of fire intensity, one that is solely a basic property of the fire itself without reference to fire-fighting methods or terrain. and yet will clearly indicate the nature of the fire and help in judging how it may be fought. The property of forest fire that best meets these requirements is the rate of energy output.

Byram (1959) first described how to quote a forest fire's energy per unit time per unit length of fire front. He called it simply the "fire intensity", and calculated it as follows:

Fire intensity $=$ Heat of combustion $\times$ Fuel consumed $\times$ Rate of spread
(Btu/sec. $-f_{t}$ )
$(\mathrm{Btu} / \mathrm{lb}$.)
(lbs./ft.")
(ft. $/ \mathrm{sec}$.)

This expression gives the rate of energy output of each foot of the fire front. Of course we require estimates of all three items before the calculation can be made. The first, the heat of combustion, varies a little and depends somewhat on the fuel moisture, but for many practical purposes can be considered constant. The second item, weight of fuel consumed, is the most difficult. It may be determined directly in research work, but for general purposes reference guides are obviously necessary. Fortunately the weight of fuel consumed varies through a fairly narrow range from fire to fire, say 10 -fold or from perhaps 0.1 to $1.0 \mathrm{lbs}$. per sq. ft. Linear rate of spread, the third item, has a range of 100 -fold plus, and contributes most to the variation in intensity; fortunately it is also the easiest of the three factors to measure. Thus, if we had adequate data on the weights of available fuel in various fuel-types, fire intensity could be calculated after measuring the rate of spread alone. A distinct advantage of energy output over other possible measures of fire intensity is that it can readily be calculated by someone who has not seen the fire at all, provided he knows how fast it advanced and can estimate its fuel consumption per unit area. With some experience, however, a mere glance at a fire front would permit a rough estimate of its intensity.

Fire intensity estimation would be easiest with fires moving at even rates through uniform fuel such as found in a plantation. At the other extreme, 
fires that crown occasionally or spot plentifully would present the greatest difficulty. Some descriptive information would certainly be needed as well. Even though fire behaviour may fluctuate widely in a short time, an average value would still be useful because of the immense possible range in intensity from fire to fire: 5 to $30,000 \mathrm{Btu}$ per second per foot, according to Byram (1959), or more than 1,000-fold. A useful degree of accuracy should therefore be quite feasible. We should then have an objective means of comparing fires in different fuel-types and in different burning conditions that is theoretically sound, and quite independent of changes in firefighting methods.

The most obvious application of quantitative fire description is in research on fire behaviour and effects. As an example of bow the procedure may be applied, the table below contains data from a series of small experimental fires in a 35-year-old red pine plantation. The most intense of these has been previously described in detail (Van Wagner, 1964).

\begin{tabular}{ccccc}
\hline $\begin{array}{c}\text { Type of } \\
\text { fire }\end{array}$ & $\begin{array}{c}\text { Fire Danger } \\
\text { Index }\end{array}$ & $\begin{array}{c}\text { Rale of spread, } \\
\text { ft./min. }\end{array}$ & $\begin{array}{c}\text { Fuel consumed, } \\
\text { lbs./sq. ft. }\end{array}$ & $\begin{array}{c}\text { rire intensity, } \\
\text { Btu./sec.-ft. }\end{array}$ \\
\hline Crown fire & 14 & 35 & 0.45 & 2600 \\
Surface headfire & 13 & 20 & 0.34 & 900 \\
$"$ " & 9 & 6.6 & 0.30 & 280 \\
$" \quad$ backfire & 7 & 5.0 & 0.21 & 150 \\
$" \quad$ & 11 & 1.5 & 0.28 & 60 \\
\hline
\end{tabular}

The rates of spread are the linear rates of advance of fire fronts about 80 feet wide over a run of about the same length. The heat of combustion was taken to be $8350 \mathrm{Btu}$ per pound for the dry fuel and 7600 for the live crown fuel. The energy outputs are gross values; the fire intensity thus includes all the heat energy whether dissipated by convection, radiation or conduction. Note the wide range of rates of spread and the smaller range of fuel weight consumed.

Australian forest fire researchers have made practical use of quantitative fire description. One example is the Australian system of fire danger and behaviour rating described by McArthur and Luke (1963). It is based on the concept that a fire can be defined by its linear rate of spread and fuel consumption per unit area, and all fires are rated for both these parameters. The system does not go the whole way to rating fires by energy output, but the principle is the same and the dual rating certainly fixes the basic behaviour of the fire. McArthur (1962), however, used energy oulput directly in recommending the proper intensity for prescribed fires in eucalypt forests. The advantage of the energy output rating is that it provides in a single value a picture of the fire at a given instant, while the rate spread quoted separately indicates how fast it is moving.

Considerable field work on available fuel weight would be required before quantitative fire description could be readily applied in practice. Even then, no fire control organization would adopt the technique unless there were something obvious to be gained. Here are some aspects of fire control and control planning in which quantitative fire descriptions could replace purely relative or subjective ratings: 
1) fuel typing, 10 describe the fire behaviour in different fuel types at different hazard levels;

2) fire control planning, to describe the fire-fighting strategy required for different levels of fire intensity;

3) prescribed burning. to describe the kind of fire required;

4) damage appraisal, to link the damage to the fire behaviour;

5) aerial water bombing, to describe the degree of success in relation to the fire behaviour;

6) Juring fire-fighting itself, 10 report fire behaviour on various parts of the perimeter.

Some of the benefits of quantitative fire description would, of course, not be available until a considerable body of data had been collected, and until fire control people became familiar with it. There is litlle doubt that research on fire behaviour will be intensified in years to come. Some quantitative means of fire description will be necessary, if only so that fire researchers can understand each other. If fire control organizatiuns are going to benefit from any major advances in knowledge of fire behaviour they too will need a more scientific yardstick of fire behaviour than those in common use at present.

\section{REFERENCES}

BARROWS, G. M. [951. Fire behaviour in the Northern Rocky Mountuin Forcsts. U.S. Forest Service, Northern Rocky Mrn. For. and Ran. Exp. Sra., Sra, Pap. No. 29.

BYRAM, G. M. 1959. Combustion of forest tuels. In "Forest Fire: Control and Use". Edited by K. P. Davis. New York, McGraw-Hill: 6l-68.

HORNBY, L. G. 1935. Fuel type mapping in Region One. J. Forestry 33:67-72.

McARTHUR, A. G. 1962. Conrrol burning in encalype torests. Australia Forestry and Timber Bureau Leafler No. 80 .

McARTHUR, A. G. and R. H. LUKE. 1963. Fire behaviour studies in Australia. U.S. Forest Service, Fire Concrol Notes 24:87-92.

VAN IWAGNER, C. E. 1964. History of a small crown fire. Forescry Chronicle 40:202-205. 209. 